\title{
Comparison of risk behaviors and socio-cultural profile of men who have sex with men survey respondents recruited via venues and the internet
}

\author{
Hi Yi Tsui and Joseph TF Lau*
}

\begin{abstract}
Background: Increasingly more men who have sex with men (MSM) are using the internet to seek sex partners, and many HIV-related studies targeting MSM collect data from gay venues in order to inform the design of prevention programs. However, internet-based MSM may have different HIV risk behaviors and associated factors from those attending venues. This study examined differences in risk behaviors and socio-cultural profiles between MSM recruited from venues (e.g., gay bars/saunas) and from the internet respectively.

Methods: An anonymous cross-sectional survey was conducted. A total of 566 Chinese MSM (340 recruited from gayvenues and 226 recruited from the internet) who self-reported having had anal or oral sex with another man in the last 12 months completed a structured questionnaire.

Results: Internet-based MSM were more likely than venue-based MSM to have engaged in unprotected anal intercourse (53.3\% vs. $33.8 \%$ ) or commercial sex (as clients: $12.8 \%$ vs. $5.3 \%$; as sex workers: $6.2 \%$ vs. $1.5 \%$ ), to have sought MSM partners from the internet (51.3\% vs. 20.9\%), and to have contracted sexually transmitted diseases (STD) in the last 12 months (4.4\% vs. $0.3 \%$ ). On the other hand, internet-based MSM were less likely to have multiple sex partners (58.4\% vs. $75.6 \%$ ) and to have used psychoactive substances (7.1\% vs. 15.6\%) or drunk alcohol before sex (8.8\% vs. 16.2\%). Moreover, internet-based MSM reported poor acceptance of their own sexual orientation, felt more discriminated against, and received less social support than venue-recruited MSM.
\end{abstract}

Conclusions: Significant differences were observed between the two groups of MSM. Segmentation and targeted interventions are recommended when designing preventive interventions.

\section{Background}

The prevalence of HIV among men who have sex with men (MSM) has been increasing in different parts of the world [1-5]. Although venue-based sampling has frequently been used in studies targeting MSM [6-9], the internet is becoming a potentially useful and cost-effective option [10-13]. Internet-recruited MSM, as compared to venue-based MSM, were in general more likely to report different socio-demographic profiles and higher levels of risk behaviors such as unprotected anal intercourse (UAI) $[14,15]$, though mixed results have been reported [14-16]. Most studies investigating risk factors

\footnotetext{
* Correspondence: jlau@cuhk.edu.hk

${ }^{1}$ Centre for Health Behaviours Research, School of Public Health and Primary Care Faculty of Medicine, The Chinese University of Hong Kong, Hong Kong, Hong Kong

Full list of author information is available at the end of the article
}

in association with UAI sampled MSM from gay-venues [e.g., 6,8,9] but it is unknown whether internet-based MSM have different risk factors. There is a dearth of data comparing risk factors among MSM recruited from different sampling spaces [11,12,14-16].

The HIV prevalence among MSM in Hong Kong, China in 2007 was around 4\% [17], which is comparable to rates reported in some other Chinese cities [18]. A previous population-based study showed that around $2 \%$ of the general adult male population in Hong Kong selfreported having sex with men in the last 6 months and practicing risk behaviors such as UAI [19-21]. Moreover, a substantial proportion of MSM both in Hong Kong and in mainland China seek their male sex partners via gay venues or via the internet $[20,22]$ and MSM in Hong Kong are interacting intensively with MSM in other Chinese cities $[21,23]$. 
The present study compared socio-cultural factors and levels of risk behaviors among Hong Kong MSM participants recruited via venue-based and internet-based sampling methods. The variables compared include sociodemographics, prevalence of self-reported sexually transmitted diseases (STD), risk behaviors, service utilization and socio-cultural characteristics. The associations between these factors and UAI were investigated separately for venue-based and internet-based participants and these 2 sets of factors were compared.

\section{Methods}

\section{Study population and data collection}

The study population comprised Chinese men aged between 18 and 60 years in Hong Kong who self-reported having engaged in anal or oral sex with men in the last 12 months. A total of 566 MSM completed an anonymous structured questionnaire - 340 were venue-based and 266 were internet-based. Venue-based MSM respondents were recruited via on-site convenience sampling from 4 gay bars, 2 gay saunas, and one beach frequently visited by local MSM. The same sampling method has been used in other similar studies [e.g., 9]. With verbal informed consent, face-to-face interviews were conducted by 3 well-trained peer interviewers between June and October, 2005. Each questionnaire took about 15 minutes to complete. An incentive of HK\$50 (about 6.4US\$) was offered to respondents for completion of the interview. The response rate, defined as the number of respondents completing the questionnaire divided by the number of eligible respondents invited to join the study, was approximately $64 \%$.

During the same period, an identical anonymous selfadministered online questionnaire (with the same briefing) was used to recruit participants from the internet. Peer workers of the project promoted the study and posted a URL link to the questionnaire on the discussion forums of local gay websites. These websites are popular and frequented by MSM in Hong Kong. The websites have chat-rooms, addresses of local gay venues, and partner-finding and other functions. Potential internet-based MSM respondents were asked to confirm eligibility before joining the study. Informed consent was implied by the return of completed questionnaires. No incentive was offered due to the lack of face-to-face contact and the anonymous nature of the study. Ethics approval was obtained from the Ethics Committee of the Chinese University of Hong Kong.

\section{Measurements}

Information on respondents' age, education level, employment status (whether working full-time), and selfidentified sexual orientation (homosexual, bisexual, heterosexual, or not certain) was collected. Respondents were asked whether they had been tested for HIV antibody or had received other types of HIV-related prevention services such as peer outreach education, condom and lubricant distribution, and educational messages on websites and magazines in the last 12 months. Three questions addressed HIV-related knowledge (see Table 1) and the number of items with appropriate responses was counted to create a binary variable ( $\leq 2$ versus 3 appropriate answers). Three other questions (see Table 1) asked about participants' HIV-related perceptions, such as perceived susceptibility of acquiring HIV infection.

Questions were also asked about participants' HIVrelated behaviors in the last 12 months, including the number of MSM sex partners, having sex with different types of MSM partners, engagement in anal intercourse with MSM (and if so, whether condoms were used consistently during these sexual encounters), consumption of alcohol before having sex with MSM, use of psychoactive substances, and contraction of STD (Table 2).

Five items assessed participants' level of self-acceptance for their MSM sexual orientation. Three items assessed participants' perceived discrimination against MSM. Five other items assessed participants' perceived social support toward their MSM behaviors. These items are listed in Table 3. The total number of responses indicating nonacceptance of own sexual orientation $(\leq 2$ versus 3 to 5 non-acceptance responses), perceived discrimination $(\leq 2$ versus 3 perceived discrimination responses), and perceived social support ( $\leq 3$ versus 4 to 5 responses indicating social support) were used to form 3 binary indicator variables.

\section{Statistical analysis}

Univariate logistic regression analyses were performed to compare between-group differences (internet-recruited participants or Group I versus venue-recruited participants or Group V). As the independent variables listed in Tables 1, 2 and 3 were inter-correlated, a summary multivariate model was fitted to identify variables that were independently associated with the mode of recruitment. Variables showing significant univariate between-group differences were used as candidate variables in a stepwise multivariate logistic regression model discriminating Group I versus Group V respondents. Separate univariate and multivariate logistic regression analyses were conducted to identify factors in association with UAI in the two groups (Group I and Group V). All statistical analyses were performed using SPSS for Window 14.0 and a pvalue $<0.05$ was taken as statistically significant.

\section{Results}

\section{Background characteristics}

Results are summarized in Table 1. Compared to Group V respondents, Group I respondents were statistically 
Table 1: Background characteristics of the respondents

\begin{tabular}{|c|c|c|c|c|}
\hline & \multirow{2}{*}{$\begin{array}{c}A I I \\
(n=566)\end{array}$} & \multirow{2}{*}{$\begin{array}{l}\text { Group V } \\
(n=340)\end{array}$} & \multicolumn{2}{|c|}{ Group I } \\
\hline & & & $(n=226)$ & Univariate OR \\
\hline & Col\% & Col\% & Col\% & (Group I vs. Group V) \\
\hline \multicolumn{5}{|l|}{ Socio-demographics } \\
\hline \multicolumn{5}{|l|}{ Age groups } \\
\hline $18-29$ & 70.0 & 68.2 & 72.6 & 1.00 \\
\hline$\geq 30$ & 30.0 & 31.8 & 27.4 & 0.81 \\
\hline \multicolumn{5}{|l|}{ Education level } \\
\hline$\leq$ High school & 32.3 & 37.4 & 24.8 & 1.00 \\
\hline$\geq$ College/university & 67.7 & 62.6 & 75.2 & $1.81^{* *}$ \\
\hline \multicolumn{5}{|l|}{ Employment status } \\
\hline Employed full-time & 68.6 & 79.4 & 52.2 & 1.00 \\
\hline Not employed full-time & 31.4 & 20.6 & 47.8 & $3.53^{* * *}$ \\
\hline \multicolumn{5}{|c|}{ Self-identified as exclusively homosexual } \\
\hline Yes & 81.1 & 82.1 & 79.6 & 1.00 \\
\hline No (bisexual/not certain) & 18.9 & 17.9 & 20.4 & 1.17 \\
\hline \multicolumn{5}{|c|}{ HIV-related prevention services (last 12 months) } \\
\hline \multicolumn{5}{|l|}{ Tested for HIV } \\
\hline No & 73.7 & 71.8 & 76.5 & 1.00 \\
\hline Yes & 26.3 & 28.2 & 23.5 & 0.78 \\
\hline \multicolumn{5}{|c|}{ Received other HIV prevention services } \\
\hline No & 54.4 & 54.1 & 54.9 & 1.00 \\
\hline Yes & 45.6 & 45.9 & 45.1 & 0.97 \\
\hline
\end{tabular}

HIV-related knowledge \& perceptions

A healthy-looking HIV-infected person could transmit HIV to others\#

Inappropriate answer

Appropriate answer (Yes)

HIV virus could be transmitted via mouth-tomouth kissing with an HIV-infected person\#

Inappropriate answer

64.7

Appropriate answer (No)
HIV infection can be detected via blood test one week after the infection took place\#

Inappropriate answer

Appropriate answer (No) 
Table 1: Background characteristics of the respondents (Continued)

\begin{tabular}{|c|c|c|c|c|}
\hline \multicolumn{5}{|c|}{$\begin{array}{l}\text { Total number of appropriate responses to the } \\
\text { above } 3 \text { items }\end{array}$} \\
\hline$\leq 2$ appropriate answers & 75.6 & 73.2 & 79.2 & 1.00 \\
\hline 3 appropriate answers & 24.4 & 26.8 & 20.8 & 0.72 \\
\hline \multicolumn{5}{|c|}{ Perceived condom efficacy for HIV prevention } \\
\hline Quite high to low & 58.3 & 63.8 & 50.0 & 1.00 \\
\hline Very high & 41.7 & 36.2 & 50.0 & $1.76^{* *}$ \\
\hline \multicolumn{5}{|c|}{$\begin{array}{l}\text { Self-perceived susceptibility of HIV infection } \\
\text { in the future }\end{array}$} \\
\hline Little/very little & 66.6 & 60.9 & 75.2 & 1.00 \\
\hline Moderate to very high & 33.4 & 39.1 & 24.8 & $0.51^{* * *}$ \\
\hline \multicolumn{5}{|c|}{ Fear of getting HIV via MSM sex behaviors } \\
\hline No & 35.5 & 33.8 & 38.1 & 1.00 \\
\hline Yes/a little & 64.5 & 66.2 & 61.9 & 0.83 \\
\hline
\end{tabular}

Group V: Venue-recruited MSM; Group I: Internet-recruited MSM. \#Response categories include "yes", "no", and "not certain". ${ }^{*} p<0.05 ;{ }^{* *} p<0.01 ;{ }^{* * *} p<0.001$.

more likely to have attended college or university $(75.2 \%$ versus $62.6 \%$ ), to not be working full-time ( $47.8 \%$ versus $20.6 \%$ ), and to perceive condom use as being efficacious for HIV prevention (50.0\% versus $36.2 \%)$. Group I respondents were less likely than Group V to have provided an appropriate response to the item concerning whether mouth-to-mouth kissing with an HIV-infected person could transmit HIV (27.9\% versus $40.3 \%$ ), and to perceive being moderately or highly susceptible to contracting HIV (24.8\% versus 39.1\%).

Risk behaviors and self-reported STD in the last 12 months Group I respondents were more likely than Group V respondents to report certain risk behaviors, including having had sex with male sex workers $(12.8 \%$ versus $5.3 \%)$, recruiting MSM sex partners from the internet (51.3\% versus $20.9 \%$ ), providing commercial sex services to other MSM (6.2\% versus 1.5\%), being inconsistent condom users during anal sex (53.3\% versus $33.8 \%)$, and having contracted STD in the last 12 months $(4.4 \%$ versus $0.3 \%$; Table 2). The reverse was true for having had multiple MSM sex partners in the last 12 months (58.4\% versus $75.6 \%$ ), and use of psychoactive substances or alcohol prior to having sex in the last 12 months (psychoactive substances: $7.1 \%$ versus $15.6 \%$; alcohol: $8.8 \%$ versus 16.2\%; Table 2).

\section{Socio-cultural variables}

Group I respondents were more likely than Group V participants to have given "non-acceptance" responses to the
5 individual items assessing acceptance of their sexual orientation (univariate OR ranged from 2.14 to 3.14, p < 0.01 ) and to have provided $\geq 3$ responses (out of 5 ) indicating non-acceptance of their sexual orientation $(36.7 \%$ versus $18.2 \%$, univariate $\mathrm{OR}=2.60, \mathrm{p}<0.001$; Table 3 ).

Of all respondents, respectively $62.5 \%, 62.7 \%$ and $65.3 \%$ reported perceiving a fair amount to a great deal of discrimination against MSM in Hong Kong, feeling discriminated against, or experiencing pressure from family/friends due to their sexual orientation (Table 3). Group I respondents were more likely than Group V respondents to have provided responses indicating perceived discrimination or social pressure to the aforementioned 3 items (univaraite OR ranged from 1.85 to $5.86, \mathrm{p}<0.01$ ) and to have given responses indicating perceived discrimination/social pressure to all 3 questions $(59.7 \%$ versus $24.7 \%$; univariate $\mathrm{OR}=4.52$; Table 3).

With regard to the 5 individual items related to perceived social support, Group I participants were less likely than Group V respondents to have provided responses indicating the availability of social support (univariate OR ranged from 0.26 to $0.64, \mathrm{p}<0.05$ ) or to have given $\geq 4$ affirmative responses (out of 5 ) to the availability of social support (8.4\% versus $21.2 \%$, univariate $\mathrm{OR}=0.34, \mathrm{p}<0.001$; Table 3$)$.

\section{A multivariate summary model}

The results showed that Group I respondents were more likely than Group V respondents to be not employed full- 
Table 2: Sex partnerships, unprotected anal intercourse, substance use behaviors, and self-reported STD in the last 12 months

\begin{tabular}{|c|c|c|c|c|}
\hline & $\begin{array}{c}A I I \\
(n=566)\end{array}$ & $\begin{array}{l}\text { Group V } \\
(n=340)\end{array}$ & $\begin{array}{c}\text { Group I } \\
(n=226)\end{array}$ & Univariate OR \\
\hline & $\mathrm{Col} \%$ & Col\% & Col\% & (Group I vs. Group V) \\
\hline \multicolumn{5}{|c|}{ Number \& type of MSM partner (last 12 months) } \\
\hline \multicolumn{5}{|c|}{ Number of MSM sex partners } \\
\hline One & 31.3 & 24.4 & 41.6 & 1.00 \\
\hline More than 1 & 68.7 & 75.6 & 58.4 & $0.45^{* * *}$ \\
\hline \multicolumn{5}{|c|}{ Having sex with MSM acquaintances recruited online } \\
\hline No & 67.0 & 79.1 & 48.7 & 1.00 \\
\hline Yes & 33.0 & 20.9 & 51.3 & $4.00^{* * *}$ \\
\hline \multicolumn{5}{|c|}{ Having sex with male sex workers } \\
\hline No & 91.7 & 94.7 & 87.2 & 1.00 \\
\hline Yes & 8.3 & 5.3 & 12.8 & $2.63^{* *}$ \\
\hline \multicolumn{5}{|c|}{ Having provided commercial sex to males } \\
\hline No & 96.6 & 98.5 & 93.8 & 1.00 \\
\hline Yes & 3.4 & 1.5 & 6.2 & $4.43^{* *}$ \\
\hline \multicolumn{5}{|c|}{ Anal intercourse with MSM (last 12 months) } \\
\hline \multicolumn{5}{|c|}{ Engaged in any MSM anal intercourse } \\
\hline No & 19.8 & 20.0 & 19.5 & 1.00 \\
\hline Yes & 80.2 & 80.0 & 80.5 & 1.03 \\
\hline \multicolumn{5}{|c|}{$\begin{array}{l}\text { Among those who had engaged in any MSM anal intercourse ( } n \\
=454) \text {, Unprotected anal intercourse (UAl) (last } 12 \text { months) }\end{array}$} \\
\hline \multicolumn{5}{|c|}{ Engaged in any MSM UAI } \\
\hline No & 58.4 & 66.2 & 46.7 & 1.00 \\
\hline Yes, UAI & 41.6 & 33.8 & 53.3 & $2.23^{* * *}$ \\
\hline \multicolumn{5}{|c|}{ Substance use (last 12 months) } \\
\hline \multicolumn{5}{|c|}{ Used psychoactive substances } \\
\hline No & 87.8 & 84.4 & 92.9 & 1.00 \\
\hline Yes & 12.2 & 15.6 & 7.1 & $0.41^{* *}$ \\
\hline \multicolumn{5}{|c|}{ Drank alcohol before sex } \\
\hline No & 86.7 & 83.8 & 91.2 & 1.00 \\
\hline Yes & 13.3 & 16.2 & 8.8 & $0.50^{*}$ \\
\hline \multicolumn{5}{|c|}{ Self-reported STD (last 12 months) } \\
\hline \multicolumn{5}{|c|}{ Self-reported contraction of STD } \\
\hline No & 98.1 & 99.7 & 95.6 & 1.00 \\
\hline Yes & 1.9 & 0.3 & 4.4 & $15.69^{* *}$ \\
\hline
\end{tabular}


Table 3: Perceived rejection, self non-acceptance and social support in relation to MSM behaviors

\begin{tabular}{|c|c|c|c|c|}
\hline & $\begin{array}{c}A I I \\
(n=566)\end{array}$ & $\begin{array}{l}\text { Group V } \\
(n=340)\end{array}$ & $\begin{array}{c}\text { Group I } \\
(n=226)\end{array}$ & Univariate OR \\
\hline & Col\% & Col\% & Col\% & (Group Ivs. Group V) \\
\hline \multicolumn{5}{|l|}{ Self-acceptance of MSM sexual orientation } \\
\hline \multicolumn{5}{|c|}{ Felt uneasy about their sexual orientation } \\
\hline No & 64.5 & 71.5 & 54.0 & 1.00 \\
\hline Yes & 35.5 & 28.5 & 46.0 & $2.14^{* * *}$ \\
\hline \multicolumn{5}{|l|}{ Felt ashamed of their sexual orientation } \\
\hline No & 78.4 & 84.4 & 69.5 & 1.00 \\
\hline Yes & 21.6 & 15.6 & 30.5 & $2.38^{* * *}$ \\
\hline \multicolumn{5}{|c|}{ Afraid others knowing their sexual orientation } \\
\hline No & 36.0 & 45.9 & 21.2 & 1.00 \\
\hline Yes & 64.0 & 54.1 & 78.8 & $3.14^{* * *}$ \\
\hline \multicolumn{5}{|l|}{ Fully accept their sexual orientation } \\
\hline Yes & 88.7 & 92.0 & 83.6 & 1.00 \\
\hline No/a little & 11.3 & 8.0 & 16.4 & $2.26^{* *}$ \\
\hline \multicolumn{5}{|c|}{ Would date/marry a woman to hide their sexual orientation } \\
\hline No & 75.1 & 82.4 & 64.2 & 1.00 \\
\hline Yes(already did so/may be) & 24.9 & 17.6 & 35.8 & $2.61^{* * *}$ \\
\hline \multicolumn{5}{|c|}{$\begin{array}{l}\text { Number of items showing self non-acceptance of MSM behaviors } \\
\text { (to the above } 5 \text { items) }\end{array}$} \\
\hline 0 to 2 non-acceptance responses & 74.4 & 81.8 & 63.3 & 1.00 \\
\hline 3 to 5 non-acceptance responses & 25.6 & 18.2 & 36.7 & $2.60^{* * *}$ \\
\hline
\end{tabular}

Perceived MSM-related discrimination

Perceived discrimination against MSM in Hong Kong

$$
\begin{aligned}
& \text { Very little/little } \\
& \text { A fair amount/a great deal }
\end{aligned}
$$

Felt being discriminated because of their sexual orientation

No

Yes

Experienced pressure from family \& friends due to their sexual orientation

No

Yes

Number of items showing perceived discrimination against MSM (to the above 3 items)

\footnotetext{
0 - 2 discrimination responses

3 discrimination responses
}

\section{Perceived social support}

\section{Family knowing their sexual orientation}

$$
\begin{aligned}
& \text { A few or none } \\
& \text { All or most of them }
\end{aligned}
$$

Family supporting their sexual orientation

No/unaware of one's sexual orientation 
Table 3: Perceived rejection, self non-acceptance and social support in relation to MSM behaviors (Continued)

\begin{tabular}{|c|c|c|c|c|}
\hline Yes & 16.3 & 20.9 & 9.3 & $0.39^{* * *}$ \\
\hline \multicolumn{5}{|c|}{ Best friends supporting their sexual orientation } \\
\hline No/unaware of one's sexual orientation & 36.0 & 30.6 & 44.2 & 1.00 \\
\hline Yes & 64.0 & 69.4 & 55.8 & $0.56^{* *}$ \\
\hline \multicolumn{5}{|c|}{ Having someone to talk to about their sexual orientation } \\
\hline No & 26.9 & 17.4 & 41.2 & 1.00 \\
\hline Yes/no need & 73.1 & 82.6 & 58.8 & $0.30^{* * *}$ \\
\hline \multicolumn{5}{|l|}{ Number of friends having MSM behaviors } \\
\hline A few or none & 58.8 & 46.6 & 77.0 & 1.00 \\
\hline All or most of them & 41.2 & 53.4 & 23.0 & $0.26^{* * *}$ \\
\hline \multicolumn{5}{|c|}{$\begin{array}{l}\text { Perceived extent of support received regarding MSM behaviors (to } \\
\text { the above } 5 \text { items) }\end{array}$} \\
\hline 0 - 3 support responses & 83.9 & 78.8 & 91.6 & 1.00 \\
\hline $4-5$ support responses & 16.1 & 21.2 & 8.4 & $0.34^{* * *}$ \\
\hline
\end{tabular}

Group V: Venue-recruited MSM; Group I: Internet-recruited MSM.

${ }^{*} p<0.05 ;{ }^{* *} p<0.01 ;{ }^{* * *} p<0.001$.

time $(\mathrm{OR}=2.37)$, to have had sex with male sex workers in the last 12 months $(\mathrm{OR}=3.44)$, to have recruited MSM sex partners via the internet in the last 12 months $(\mathrm{OR}=$ 7.62), to be inconsistent condom users during anal intercourse with MSM in the last 12 months (OR = 2.66), to self-report having contracted STD in the last 12 months $(\mathrm{OR}=25.71)$, to be afraid of having others know about their sexual orientation $(\mathrm{OR}=1.86)$, to perceive a fair amount/a great deal of discrimination against MSM in Hong Kong ( $\mathrm{OR}=2.91)$, and to feel discriminated against due to their sexual orientation $(\mathrm{OR}=3.61)$. Group I respondents were less likely than Group V respondents to perceive moderate to very high susceptibility to contracting $\mathrm{HIV}$ in the future $(\mathrm{OR}=0.56)$, to have multiple MSM sex partners in the last 12 months $(\mathrm{OR}=0.25)$, and to have all or most of their friends being MSM $(\mathrm{OR}=0.18$; Table 4).

\section{Factors associated with UAI with MSM in the last 12 months} among Group I and Group V respondents

The results showed that among Group I respondents, those whose best friends were supportive of their sexual orientation $(\mathrm{OR}=1.94)$ and those having all or most friends being MSM $(\mathrm{OR}=2.38)$ were more likely than others to have engaged in UAI with MSM in the last 12 months. Among Group V respondents, those who gave responses indicating perceived discrimination against MSM in all the 3 relevant items $(\mathrm{OR}=2.33)$ and those whose best friends were supporting of their sexual orientation $(\mathrm{OR}=1.97)$ were more likely than others to have engaged in UAI with MSM in the last 12 month, while the reverse was true for those aged 30 or above $(\mathrm{OR}=0.54$; Table 5).

\section{Discussion}

Consistent with the results of some previous studies $[14,15,20]$, internet-recruited MSM were more likely than their venue-recruited counterparts to have engaged in UAI and commercial sex, and to report having contracted STD in the last 12 months. The level of perceived HIV risk was however lower among internet-recruited MSM than among MSM recruited from venues. Different recruitment methods may therefore provide different results.

Internet-recruited MSM were less likely than venuerecruited MSM to have multiple MSM sex partners. It is possible that venue-goers meet many potential sex partners face-to-face in bars and saunas etc. and may end up having sex with some of them eventually, whilst internetbased sex networks are often constructed in a virtual reality. Sexual networks are important platforms for both HIV transmission [24,25] and HIV interventions. Network-based interventions might be more feasible for venue-based respondents than for internet-based respondents. The problem of consuming psychoactive substances or alcohol prior to sexual intercourse was also more severe among venue-recruited MSM respondents than among internet-recruited respondents. Alcohol, drugs, and relevant peer pressure are more likely to prevail in venues. The findings of this study are consistent with those reported in other countries [14]. This suggests that venue-based campaigns should strengthen harm reduction of substance use and alcohol misuse.

Stating whether internet-based or venue-based respondents are at higher risk may oversimplify the issue. The two sampling methods may not be accessing a single population. Some but not all MSM can be accessed via both the internet and venues. Our data did not allow us to 
Table 4: A multivariate model predicting whether respondents are internet- or venue-recruited\#

\begin{tabular}{|c|c|c|c|}
\hline & \multicolumn{2}{|c|}{ Group I } & \multirow{2}{*}{$\begin{array}{c}\text { Multivariate OR } \\
(95 \% \mathrm{Cl})\end{array}$} \\
\hline & (n) & Row\% & \\
\hline \multicolumn{4}{|l|}{ Socio-demographics } \\
\hline \multicolumn{4}{|l|}{ Employment status } \\
\hline Employed full-time $(n=388)$ & (118) & 30.4 & 1.00 \\
\hline Not employed full-time $(n=178)$ & (108) & 60.7 & $2.37(1.46,3.86)^{* * *}$ \\
\hline \multicolumn{4}{|c|}{ HIV-related knowledge \& perceptions } \\
\hline \multicolumn{4}{|c|}{ Self-perceived susceptibility of HIV infection in the future } \\
\hline Little/very little/not certain $(n=377)$ & (170) & 45.1 & 1.00 \\
\hline Moderate to very high $(n=189)$ & (56) & 29.6 & $0.56(0.33,0.96)^{*}$ \\
\hline \multicolumn{4}{|c|}{ Number \& type of MSM sex partners in the last 12 months } \\
\hline \multicolumn{4}{|c|}{ Number of MSM sex partners } \\
\hline One $(n=177)$ & (94) & 53.1 & 1.00 \\
\hline More than one $(n=389)$ & (132) & 33.9 & $0.25(0.14,0.42)^{* * *}$ \\
\hline \multicolumn{4}{|c|}{ Having sex with MSM acquaintances recruited online } \\
\hline No $(n=379)$ & (110) & 29.0 & 1.00 \\
\hline Yes $(n=187)$ & (116) & 62.0 & $7.62(4.40,13.20)^{* * *}$ \\
\hline \multicolumn{4}{|l|}{ Having sex with male sex workers } \\
\hline No $(n=519)$ & (197) & 38.0 & 1.00 \\
\hline Yes $(n=47)$ & (29) & 61.7 & $3.44(1.53,7.70)^{* *}$ \\
\hline \multicolumn{4}{|c|}{ Unprotected anal intercourse (UAI) in the last 12 months } \\
\hline \multicolumn{4}{|c|}{ Engaged in any MSM UAI } \\
\hline No UAl/no anal sex $(n=377)$ & (129) & 34.2 & 1.00 \\
\hline Yes, UAl $(n=189)$ & (97) & 51.3 & $2.66(1.62,4.37)^{* * *}$ \\
\hline \multicolumn{4}{|l|}{ Self-reported STD } \\
\hline \multicolumn{4}{|l|}{ Self-reported contraction of STD } \\
\hline No $(n=555)$ & (216) & 38.9 & 1.00 \\
\hline Yes $(n=11)$ & (10) & 90.9 & $25.71(1.99,331.57)^{*}$ \\
\hline
\end{tabular}

Self-acceptance of MSM sexual orientation

Fear of others knowing their sexual orientation
No $(n=204)$
Yes $(n=362)$

Perceived MSM-related discrimination

\section{Perceived discrimination against MSM in Hong Kong}

Very little/little $(n=212)$

Felt being discriminated against because of their sexual orientation

$$
\begin{aligned}
& \text { No }(n=211) \\
& \text { Yes }(n=355)
\end{aligned}
$$


Table 4: A multivariate model predicting whether respondents are internet- or venue-recruited" (Continued)

\begin{tabular}{|c|c|c|c|}
\hline A few or none $(n=332)$ & (174) & 52.4 & 1.00 \\
\hline All or most of them $(n=233)$ & (52) & 22.3 & $0.18(0.11,0.30)^{* * *}$ \\
\hline \multicolumn{4}{|c|}{ Among all 566 respondents. } \\
\hline \multicolumn{4}{|c|}{ Group V: Venue-recruited MSM; Group I: Internet-recruited MSM. } \\
\hline \multicolumn{4}{|c|}{ \# All univariately significant variables summarized in Tables 1,2 and 3 are considered as candidate variables. } \\
\hline
\end{tabular}

assess the degree of overlap. Our data, however, informed us that survey results of risk behaviors in MSM depend on the mode of data collection.

This study represents one of few attempts made to discern the socio-cultural profiles of venue-recruited and internet-recruited MSM. It can be seen that as compared to their counterparts recruited from venues, internetrecruited MSM respondents were less likely to disclose their sexual orientation to family members and to accept their own sexual orientation, and more likely to fear disclosing their sexual orientation to others, and to date/ marry a woman in order to hide their sexual orientation. Implementation of face-to-face peer education may hence be more difficult and less feasible for internetbased MSM. Instead, internet-based empowerment efforts may be relevant for this group. Empowerment among MSM would increase condom use [26]. This study has also shown that only a minority of the participants, especially internet-based ones, had family or best friends who were supportive of their sexual orientation, possibly reflecting the severity of social stigma against MSM in Hong Kong.

Our findings indicated no significant between-group differences in service utilization rates. However, reservations and fear related to disclosing one's MSM identity might prevent some internet-recruited MSM from visiting gay venues. Since most MSM studies were based on venue-based sampling methods, the results of which were used to design programs targeting MSM in general, these programs may not be the most appropriate for internetbased MSM.

With respect to factors associated with UAI for venuerecruited and internet-recruited MSM respondents, perceived discrimination was significant for the former group but not the latter; the reverse was true for having some or all friends having MSM behaviors. Having best friends supporting one's MSM sexual orientation was significant for both groups. It is therefore seen that the two groups of MSM have both common and different factors associated with UAI. Social networks and social support may lead to both safer and riskier sexual behaviors $[8,24]$. Having best friends to support one's sexual orientation was associated with UAI in both groups; the norm among their peers however may not favor condom use. Furthermore, internet-recruited respondents were relatively lacking in social support and may therefore be more affected by peer influences. This may explain partially why the variable related to having more MSM friends was significant in internet-recruited MSM but not the venuerecruited sample. It is however less clear why perceived discrimination matters in the latter group but not in the former group. Further research is required.

The present study has some limitations. Firstly, convenience-sampling was used as random sampling was not feasible. Many published MSM studies have used similar recruitment methods [e.g., 8]. Secondly, data were selfreported and may be subject to reporting bias, though most sex behavior studies are also self-reported [e.g., $8,14,19,21]$. Respondents were assured of strict anonymity and privacy of the interviews. Thirdly, we did not ask about HIV status of the individuals. HIV positive individuals may have higher levels of risk behavior as compared to their HIV negative counterparts. An alternate explanation of our results may hence be due to a higher proportion of HIV positive MSM using the internet to seek sex partners or for sero-sorting. We cannot test this hypothesis with our results and further research is warranted. However, the involved website does not have any special contents catering HIV positive MSM and sero-sorting is unpopular in Hong Kong. HIV positive MSM are also not deferred from seeking partners from gay venues. Therefore, the bias should not be too serious. Fourthly, stronger social desirability bias may occur among venue-recruited participants as compared to internet-recruited participants, who did not need to face an interviewer. Fifthly, it is possible that a higher proportion of internet-recruited participants were living with a regular partner, with whom unprotected anal intercourse is usually more common than with casual partners. There also was a possibility of self-selection bias in the internet-recruited respondents. Finally, biological markers were not collected in this study.

\section{Conclusions}

The results of this study have implications on research survey methodology. They reinforce the claim that for HIV-related risk behavior studies, results are heavily dependent on the mode of data collection. Most of the published MSM studies are venue-based [e.g., 6,8] and their results should be interpreted with care. The rela- 
Table 5: Factors associated with UAI in the last 12 months (among those having had anal sex) - Venue-recruited MSM (n = 272) \& internet-recruited MSM $(n=182)$

\begin{tabular}{|c|c|c|c|c|c|c|c|c|}
\hline & \multicolumn{4}{|c|}{ Group V } & \multicolumn{4}{|c|}{ Group I } \\
\hline & $\begin{array}{c}\text { UAI } \\
\text { Row\% }\end{array}$ & (n) & $\begin{array}{c}\text { Univariate } \\
\text { OR }\end{array}$ & $\begin{array}{c}\text { Multivariate OR } \\
\qquad(95 \% \mathrm{Cl})\end{array}$ & $\begin{array}{c}\text { UAI } \\
\text { Row\% }\end{array}$ & (n) & $\begin{array}{l}\text { Univariate } \\
\text { OR }\end{array}$ & $\begin{array}{c}\text { Multivariate OR } \\
\qquad(95 \% \mathrm{Cl})\end{array}$ \\
\hline \multicolumn{9}{|l|}{ Socio-demographics } \\
\hline \multicolumn{9}{|l|}{ Age groups } \\
\hline $18-29$ & 37.5 & (72) & 1.00 & 1.00 & 54.3 & (69) & 1.00 & --- \\
\hline$\geq 30$ & 25.0 & (20) & $0.56^{*}$ & $0.54(0.29,0.98)^{*}$ & 50.9 & (28) & 0.87 & \\
\hline \multicolumn{9}{|l|}{$\begin{array}{l}\text { Number of items showing } \\
\text { perceived discrimination against } \\
\text { MSM (to the above } 3 \text { items) }\end{array}$} \\
\hline $0-2$ discrimination responses & 30.1 & (63) & 1.00 & 1.00 & 60.8 & $(45)$ & 1.00 & --- \\
\hline 3 discrimination responses & 46.0 & (29) & $1.98^{*}$ & $2.33(1.28,4.26)^{* *}$ & 48.1 & $(52)$ & 0.60 & \\
\hline \multicolumn{9}{|l|}{$\begin{array}{l}\text { Best friends supporting their } \\
\text { sexual orientation }\end{array}$} \\
\hline $\begin{array}{l}\text { No/unaware of one's sexual } \\
\text { orientation }\end{array}$ & 25.0 & (20) & 1.00 & 1.00 & 42.5 & (34) & 1.00 & 1.00 \\
\hline Yes & 37.5 & $(72)$ & $1.80 *$ & $1.97(1.07,3.62)^{*}$ & 61.8 & (63) & $2.19 *$ & $1.94(1.05,3.57)^{*}$ \\
\hline \multicolumn{9}{|l|}{$\begin{array}{l}\text { Number of friends having MSM } \\
\text { behaviors }\end{array}$} \\
\hline A few or none & 34.7 & (43) & 1.00 & --- & 47.9 & (67) & 1.00 & 1.00 \\
\hline All or most of them & 33.3 & (49) & 0.94 & & 71.4 & (30) & $2.72 * *$ & $2.38(1.11,5.11)^{*}$ \\
\hline \multicolumn{9}{|c|}{$\begin{array}{l}\text { Group V: Venue-recruited MSM; Group I: Internet-recruited MSM. } \\
\text { Multivariate OR: Odds ratio obtained from stepwise multivariate logistic regression using univariately significant variables as candidate variables. } \\
\text { Variable considered included all those listed in Tables } 1,2 \text { and } 3 \text {. For Group V (venue-recruited MSM), univariately significant variables included } \\
\text { age group, number of items showing perceived discrimination against MSM, and having best friends supporting one's sexual orientation. For } \\
\text { Group I (internet-recruited MSM), univariately significant variables included having best friends supporting one's sexual orientation, and number } \\
\text { of friends having MSM behaviors. Only multivariately significant variables are summarized in Table } 5 . \\
{ }^{*} p<0.05 ; *{ }^{* *}<0.01 ; * * * p<0.001 \text {. } \\
--- \text { univariately not significant (and was not considered in the multivariate model) }\end{array}$} \\
\hline
\end{tabular}

tively new respondent-driven sampling method (RDS) is meant to give probabilistic sampling estimates and has recently been applied to different MSM populations [e.g., 27]. Comparisons between venue-based, internet-based, and RDS survey results are warranted to understand potential impacts due to different sampling methods.

The study findings remind HIV workers that MSM are not a homogeneous group. According to the social marketing framework, segmentation is required for effective HIV prevention [28]. The "orientation-mix" of the segmented audience has to be sorted out for designing effective HIV intervention. Such does not seem to have been emphasized adequately in existing programs.

\section{Competing interests}

The authors declare that they have no competing interests.

\section{Authors' contributions}

$\mathrm{JL}$ is the principal investigator of the project. HYT performed the statistical analyses and implementation of the project. Both JL and HYT were involved in the design of the study, interpreted the results, and wrote the manuscript. Both authors read and approved the final manuscript.

\section{Acknowledgements}

The authors would like to thank all respondents of the study and the fieldworkers implementing the study. The project was supported by the Research Fund for the Control of Infectious Diseases (RFCID) from the Food and Health Bureau of the Hong Kong SAR Government and the Centre for Emerging Infectious Diseases Research Fund, The Chinese University of Hong Kong.

\section{Author Details}

Centre for Health Behaviours Research, School of Public Health and Primary Care Faculty of Medicine, The Chinese University of Hong Kong, Hong Kong, Hong Kong

Received: 9 February 2009 Accepted: 6 May 2010

Published: 6 May 2010 


\section{References}

1. Advisory Council on AIDS: HIV/AIDS statistics in Hong Kong (updated 31 March 2008). ACA Newsfile 2008, 15:27.

2. Centers for Disease Control and Prevention (CDC): HIV prevalence among populations of men who have sex with men--Thailand, 2003 and 2005. MMWR Morb Mortal Wkly Rep 2006, 55(31):844-848.

3. Centers for Disease Control and Prevention (CDC): Trends in HIV/AIDS diagnoses among men who have sex with men--33 States, 2001-2006. MMWR Morb Mortal Wkly Rep 2008, 57(25):681-686.

4. Ma X, Zhang Q, He X, Sun W, Yue H, Chen S, Raymond HF, Li Y, Xu M, Du H, McFarland W: Trends in prevalence of HIV, syphilis, hepatitis $C$, hepatitis $B$, and sexual risk behavior among men who have sex with men. Results of 3 consecutive respondent-driven sampling surveys in Beijing, 2004 through 2006. J Acquir Immune Defic Syndr 2007 45:581-587.

5. State Council AIDS Working Committee Office, UN Theme Group on AIDS in China: A joint assessment of HIV/AIDS Prevention Treatment and Care in China (2007) 2007

6. Choi KH, Han CS, Hudes ES, Kegeles S: Unprotected sex and associated risk factors among young Asian and Pacific Islander men who have sex with men. AIDS Educ Prev 2002, 14:472-481.

7. Dudley MG, Rostosky SS, Korfhage BA, Zimmerman RS: Correlates of high-risk sexual behavior among young men who have sex with men. AIDS Educ Prev 2004, 16(4):328-340.

8. Jones KT, Johnson WD, Wheeler DP, Gray P, Foust E, Gaiter J: Nonsupportive peer norms and incarceration as HIV risk correlates for young black men who have sex with men. AIDS Behav 2008, 12:41-50

9. Mansergh G, Naorat S, Jommaroeng R, Jenkins RA, Stall R, Jeeyapant S, Phanuphak P, Tappero JW, van Griensven F: Inconsistent condom use with steady and casual partners and associated factors among sexually-active men who have sex with men in Bangkok, Thailand. AIDS Behav 2006, 10:743-751.

10. Bowen $\mathrm{AM}$, Horvath $\mathrm{K}$, Williams ML: A randomized control trial of internet- delivered HIV prevention targeting rural MSM. Health Educ Res 2007, 22:120-127.

11. Fernández MI, Perrino T, Collazo JB, Varga LM, Marsh D, Hernandez N, Rehbein A, Bowen GS: Surfing new territory: club-drug use and risky sex among Hispanic men who have sex with men recruited on the Internet. J Urban Health 2005, 82(1 Suppl 1):i79-88.

12. Hidaka Y, Ichikawa S, Koyano J, Urao M, Yasuo T, Kimura H, Ono-Kihara M, Kihara M: Substance use and sexual behaviours of Japanese men who have sex with men: a nationwide internet survey conducted in Japan. BMC Public Health 2006, 6:239.

13. Lau JT, Lau M, Cheung A, Tsui HY: A randomized controlled study to evaluate the efficacy of an Internet-based intervention in reducing HIV risk behaviors among men who have sex with men in Hong Kong. AIDS Care 2008, 20:820-828

14. Elford J, Bolding G, Davis M, Sherr L, Hart G: Web-based behavioral surveillance among men who have sex with men: a comparison of online and offline samples in London, UK. J Acquir Immune Defic Syndr 2004, 35:421-426.

15. Evans AR, Wiggins RD, Mercer $\mathrm{CH}$, Bolding GJ, Elford J: Men who have sex with men in Great Britain: comparison of a self-selected internet sample with a national probability sample. Sex Transm Infect 2007 83:200-205.

16. Rhodes SD, DiClemente RJ, Cecil H, Hergenrather KC, Yee LJ: Risk among men who have sex with men in the United States: a comparison of an Internet sample and a conventional outreach sample. AIDS Educ Prev 2002, 14:41-50.

17. Special Preventive Programme Centre for Health Protection Department of Health: Factsheet on PRiSM 20062007.

18. Li SW, Zhang XY, Li XX, Wang MJ, Li DL, Ruan YH, Zhang XX, Shao YM: Detection of recent HIV-1 infections among men who have sex with men in Beijing during 2005 - 2006. Chinese Medical Journal 2008 121:1105-1108.

19. Lau JT, Kim JH, Lau M, Tsui HY: HIV related behaviours and attitudes among Chinese men who have sex with men in Hong Kong: a population based study. Sex Transm Infect 2004, 80:459-465.

20. Lau JT, Kim JH, Lau M, Tsui HY: Prevalence and risk behaviors of Chinese men who seek same-sex partners via the internet in Hong Kong. AIDS Educ Prev 2003, 15:516-528.
21. Lau JT, Kim JH, Lau M, Tsui HY: Prevalence and risk behaviors of Hong Kong males who seek cross-border same-sex partners in mainland China. Sex Transm Dis 2004, 31:568-574

22. Zhang B, Zeng Y, Xu H, Li X, Zhou S, Liao L, et al.: Study on 1389 men who have sex with men regarding their HIV high-risk behaviors and associated factors in mainland China in 2004. Chinese Journal of Epidemiology 2007, 28:32-36. [Chinese]

23. Lau JTF, Cai W, Tsui HY, Chen L, Cheng JQ: Psychosocial factors in association with condom use during commercial sex among migrant male sex workers living in Shenzhen, mainland China who serve crossborder Hong Kong male clients. AIDS Behav 2009, 13(5):939-48.

24. Choi KH, Ning Z, Gregorich SE, Pan QC: The influence of social and sexual networks in the spread of HIV and syphilis among men who have sex with men in Shanghai, China. J Acquir Immune Defic Syndr 2007, 45:77-84.

25. Ward $\mathrm{H}$ : Prevention strategies for sexually transmitted infections: importance of sexual network structure and epidemic phase. Sex Transm Infect 2007, 83(Suppl 1):i43-49.

26. Haque A, Ahmed S: Community based risks reduction approach among MSM: Bandhu Social Welfare Society: HIV/AIDS/STD prevention program. (Abstract no. WePeD4745). Proceedings of the 13th International Conference on AIDS, Durban, South Africa, July 9-14 2000

27. He Q, Wang Y, Li Y, Zhang Y, Lin P, Yang F, Fu X, Li J, Raymond HF, Ling L, McFarland W: Accessing men who have sex with men through longchain referral recruitment, Guangzhou, China. AIDS Behav 2008, 12(4 Suppl):S93-96.

28. Lamptey PR, Price JE: Social marketing sexually transmitted disease and HIV prevention: a consumer-centered approach to achieving behaviour change. AIDS 1998, 12(Suppl 2):S1-9.

Pre-publication history

The pre-publication history for this paper can be accessed here: http://www.biomedcentral.com/1471-2458/10/232/prepub

doi: $10.1186 / 1471-2458-10-232$

Cite this article as: Tsui and Lau, Comparison of risk behaviors and sociocultural profile of men who have sex with men survey respondents recruited via venues and the internet BMC Public Health 2010, 10:232

\section{Submit your next manuscript to BioMed Central and take full advantage of:}

- Convenient online submission

- Thorough peer review

- No space constraints or color figure charges

- Immediate publication on acceptance

- Inclusion in PubMed, CAS, Scopus and Google Scholar

- Research which is freely available for redistribution
C Biomed Central 